\title{
Elaboración de disposiciones de carácter general en la Administración Local, tras la entrada en vigor de la Ley 39/2015
}

\section{Development of general provisions in the Local Government, following the entry into force of Law 39/2015}

\author{
Alejandro Ramón Antelo Martínez \\ Secretario de Administración Local. Categoría Superior \\ alejandro.antelo@neda.es
}

\section{RESUMEN}

El presente trabajo tiene por objeto estudiar la incidencia de la Ley $39 / 2015$, de 1 de octubre, del Procedimiento Administrativo Común de las Administraciones Públicas, en el procedimiento de elaboración de ordenanzas y reglamentos locales, abordando asimismo los límites sustantivos y formales a que debe ajustarse el ejercicio de dicha potestad reglamentaria, con especial atención a la jurisprudencia rectora en la materia.

\section{Palabras clave}

Ordenanzas y reglamentos locales, legislar mejor, legislar inteligente.

\begin{abstract}
This paper aims to study the incidence of Law 39/2015, of October 1, the Common Administrative Procedure Public Administration in the process of drafting local ordinances and regulations, including by addressing the substantive and formal limits to adjustments to the exercise of that regulatory power, with special attention to the leading case law.
\end{abstract}

\section{Keywords}

Local ordinances and regulations, better regulation, smart regulation.

\section{SUMARIO}

1. CONSIDERACIONES INTRODUCTORIAS. 2. PREVISIONES DE LA NUEVA LEY 39/2015, DEL PROCEDIMIENTO ADMINISTRATIVO COMÚN DE LAS ADMINISTRACIONES PÚBLICAS. 2.1. Titularidad de la potestad reglamentaria local. 2.2. Límites al ejercicio de la potestad normativa local. 2.3. Planificación normativa ex ante. 2.4. Principios de buena regulación. 2.5. Procedimiento de elaboración de normas reglamentarias. 2.6. Evaluación normativa ex post. 3. SUBSISTENCIA DEL PROCEDIMIENTO DE APROBACIÓN DE REGLAMENTOS LOCALES. 4. EFICACIA DE LAS DISPOSICIONES REGLAMENTARIAS LOCALES. 5. BIBLIOGRAFÍA. 


\section{CONSIDERACIONES INTRODUCTORIAS}

Al igual que sucede en otros ámbitos de nuestro ordenamiento jurídico, el ejercicio de la potestad reglamentaria y de la iniciativa legislativa por parte de las Administraciones con competencias para ello, se ha visto secuencial y progresivamente influido por las previsiones comunitarias al respecto.

Las corrientes sajonas de better regulation no son ajenas al Estado español, las cuales, como señala Chaves García «han tenido su reflejo doméstico en la Unión Europea en el reciente Acuerdo Interinstitucional Legislar mejor, de la Comisión, Parlamento y Consejo de 15 de diciembre de 2015» ${ }^{1}$, si bien, hasta llegar a este citado Acuerdo, las Instituciones comunitarias han recorrido un largo camino no exento de dificultades. Con Cano Montejano puede señalarse como punto de partida el Consejo Europeo de Edimburgo celebrado en diciembre de 1992, «en el cual se citaba como una de las prioridades de la línea de acción comunitaria la mejora y simplificación del marco regulatorio en la Unión Europea», posteriormente impulsado definitivamente en el Consejo Europeo de Lisboa de marzo de 2000, «en el cual se fijó la denominada Estrategia de Lisboa, para el establecimiento a partir de 2001 de una acción coordinada que tuviese como meta la simplificación regulatoria a nivel comunitario» ${ }^{2}$.

Principios como los de necesidad, eficacia, proporcionalidad, seguridad jurídica, transparencia y eficiencia, hoy recogidos expresamente en la nueva Ley 39/2015, de 1 de octubre, del Procedimiento Administrativo Común de las Administraciones Públicas (LPACAP) son manifestaciones no solamente de procedimientos destinados a «legislar mejor» -better regulation- en un sentido amplio (comprensivo de la potestad normativa lato sensu, y no exclusivamente de la potestad legislativa strictu sensu), sino también encaminados a «regular de manera inteligente» -smart regulation-. En este sentido, la propia Exposición de Motivos de la Ley 39/2015 declara que,

«los diferentes informes internacionales sobre la materia definen la regulación inteligente como un marco jurídico de calidad, que permite el cumplimiento de un objetivo regulatorio a la vez que ofrece los incentivos adecuados para dinamizar la actividad económica, simplificar procesos y reducir cargas administrativas» ${ }^{3}$.

Corresponde examinar en este trabajo la plasmación de estos principios en el Título VI de la LPACAP, y concretamente su incidencia en el procedimiento de elaboración de disposiciones reglamentarias en el ámbito local, si bien interesa llamar la atención ya desde este punto preliminar, sobre la importancia que una ley de procedimiento administrativo común como ésta, presta en diversos apartados a la "actividad económica», reflejo quizás no solo de las corrientes de mejora regulatoria y producción normativa inteligente, sino también de la liberalización del comercio y de los servicios en el espacio comunitario europeo, iniciada con la Directiva 2006/123/CE del Parlamento Europeo y del Consejo, de 12 de diciembre de 2006, relativa a los servicios en el mercado interior, y que ha dado lugar en nuestro Derecho interno a una ingente actividad normativa de transposición en cascada a partir de las primeras leyes «paraguas» (Ley 17/2009, de 23 de noviembre, sobre el libre acceso a las actividades de servicios y su ejercicio) y «ómnibus» (Ley 25/2009, de 22 de diciembre, de modificación de diversas leyes para su adaptación a la Ley 17/2009).

Esta perspectiva en ocasiones demasiado economicista de la Ley 39/2015, quizás haya que buscarla también en su génesis, puesto que como afirma Rivero Ortega las modificaciones que comporta,

«no se pueden comprender sin tener presentes las conclusiones de la Comisión para la Reforma de las Administraciones Públicas -CORA-, planteadas desde un objetivo de simplificación, aunque entendido en clave de austeridad y reducción de costes» ${ }^{4}$.

\section{PREVISIONES DE LA NUEVA LEY 39/2015, DEL PROCEDIMIENTO ADMINISTRATIVO COMÚN DE LAS ADMINISTRACIONES PÚBLICAS}

La LPACAP traslada al Derecho interno español las previsiones comunitarias de better regulation y smart regulation, por lo que ahora interesa, en el procedimiento de elaboración de disposiciones regla-

\footnotetext{
CHAVES GARCÍA (2016): 843.

CANO MONTEJANO (2013): 12

Vid. apartado IV, párrafo primero.

RIVERO ORTEGA (2016): 75.
} 
mentarias locales, si bien compete evaluar y exponer el alcance y novedad que esta nueva regulación supone. Con esta finalidad, es preciso delimitar inicialmente la titularidad de la potestad reglamentaria local (perspectiva subjetiva), y los límites a su ejercicio; seguidamente, la planificación normativa ex ante, y el control ex post de las disposiciones normativas aprobadas, así como los principios de buena regulación en cuanto informadores el ejercicio de esta potestad; $y$, por último el procedimiento de elaboración de normas y su régimen de publicidad, sin olvidar la subsistencia del procedimiento de aprobación juntamente con el de elaboración.

\subsection{Titularidad de la potestad reglamentaria local}

El artículo 128.1 LPACAP dispone que «el ejercicio de la potestad reglamentaria corresponde a (...) los órganos de gobierno locales (...) de acuerdo con lo previsto en la Ley $7 / 1985$, de 2 de abril, reguladora de las Bases del Régimen Local».

A la vista de esta remisión normativa, es necesario acotar en primer lugar cuales son los Entes Locales dotados de potestad reglamentaria, y a continuación, determinar los órganos de dichos Entes que pueden ejercer la referida potestad.

En cuanto a la primera de las cuestiones enumeradas, el artículo 4.1 de la Ley 7/1985, de 2 de abril, reguladora de las Bases del Régimen Local (LRBRL), atribuye directamente esta potestad reglamentaria a las Entidades Locales territoriales (los municipios, las provincias y las islas), mientras que para las Entidades Locales denominadas no territoriales, o territoriales potestativas, así como para las asociativas de carácter local ${ }^{5}$, se establece un régimen distinto de reconocimiento de esta potestad.

Así, el artículo 4.2 de la propia LRBRL dispone que las entidades locales menores ${ }^{6}$, las comarcas, las áreas metropolitanas y demás entidades locales ( $\mathrm{v}$.gr. los consorcios) dispondrán de potestad reglamentaria cuando así les sea atribuida por las respectivas leyes autonómicas reguladoras del régimen local; con excepción de las mancomunidades que, de acuerdo con el artículo 4.3 de la norma estudiada, se estará a lo que dispongan sus estatutos, y en defecto de previsión estatutaria expresa, serán titulares de la potestad reglamentaria siempre que sea precisa para el cumplimiento de su finalidad.

Sirva como ejemplo la Ley 5/1997, de 22 de julio, de Administración Local de Galicia, que en su artículo 6 atribuye potestad reglamentaria a las entidades locales no territoriales, de conformidad con sus estatutos, por lo que en última instancia habrá que estar a lo que en ellos se disponga, con una importante excepción en lo que se refiere a las áreas metropolitanas, puesto que la Ley autonómica 4/2012, de 12 de abril, reguladora del Área Metropolitana de Vigo (única creada hasta el momento en la Comunidad Autónoma de Galicia), ya atribuye directamente esta potestad normativa a la Asamblea Metropolitana (artículo 8).

Por lo que respecta a la segunda de las cuestiones, la relativa a los órganos de los entes locales que pueden ejercer esta potestad, resulta obligado establecer una primera división entre, nuevamente los entes locales territoriales y los no territoriales, y además, dentro de los primeros, y a partir de la Ley 57/2003, de 16 de diciembre, de medidas para la modernización del gobierno local, entre los municipios de régimen común y los municipios de gran población.

5 LLISET BORREL (2001): 187-193.

6 Es necesario significar que la Ley 27/2013, de 27 de diciembre, de racionalización y sostenibilidad de la Administración Local, incluye en la LRBRL un nuevo artículo 24 bis que dispone: «1. Las leyes de las Comunidades Autónomas sobre régimen local regularán los entes de ámbito territorial inferior al Municipio, que carecerán de personalidad jurídica, como forma de organización desconcentrada del mismo para la administración de núcleos de población separados, bajo su denominación tradicional de caseríos, parroquias, aldeas, barrios, anteiglesias, concejos, pedanías, lugares anejos y otros análogos, o aquella que establezcan la leyes. (...) 3. Solo podrán crearse este tipo de entes si resulta una opción más eficiente para la administración desconcentrada de núcleos de población separados de acuerdo con los principios previstos en la Ley Orgánica 2/2012, de 27 de abril, de Estabilidad Presupuestaria y Sostenibilidad Financiera»; y que asimismo, la propia Ley 27/2013 contiene una Disposición Transitoria Cuarta, del siguiente tenor literal: «1. Las entidades de ámbito territorial inferior al municipio existentes en el momento de la entrada en vigor de la presente Ley mantendrán su personalidad jurídica. 2. Con fecha 31 de diciembre de 2014, las entidades de ámbito territorial inferior al municipio deberán presentar sus cuentas ante los organismos correspondientes del Estado y de la Comunidad Autónoma respectiva para no incurrir en causa de disolución. 3. La no presentación de cuentas (...) será causa de disolución».

Ello ha llevado a RIVERO YSERN (2014): 45, a considerar que las entidades de ámbito territorial inferior al municipio «pasan de ser entidades locales a meros órganos desconcentrados del Ayuntamiento, que solo serán admisibles si demuestran ser más eficaces que la simple desconcentración en la gestión». 
En los municipios de gran población ${ }^{7}$, a los que resultan equiparados determinados Cabildos insulares canarios por virtud de la Disposición Adicional Decimocuarta $\mathrm{LRBRL}^{8}$, la competencia para la aprobación y modificación de ordenanzas y reglamentos corresponde al Pleno de la Corporación, de acuerdo con la tradición histórica de nuestro Derecho Local desde $1812^{9}$, pero sin embargo, alterando parcialmente dicha tradición, el artículo 123.3 de la LRBRL (introducido por la Ley 57/2003) permite que tal competencia normativa pueda ser delegada en las Comisiones del Pleno, con la excepción del Reglamento Orgánico cuya aprobación es competencia indelegable del Pleno.

En los municipios de régimen común (todos los restantes, así como a estos efectos las Diputaciones Provinciales, los Consejos Insulares de las Islas Baleares y los Cabildos Insulares Canarios no equiparados a los municipios de gran población), la potestad normativa continúa residenciada en el Pleno con carácter indelegable ${ }^{10}$.

Por lo que atañe a los entes locales no territoriales y a los entes de base asociativa, de acuerdo con lo estudiado, serán sus estatutos los que determinen no solamente si están facultados para ejercer la potestad normativa, sino también cuales de sus órganos son los competentes para ello, siendo norma común su atribución al órgano de representación plenaria ${ }^{11}$.

\subsection{Límites al ejercicio de la potestad normativa local}

Sin apenas innovación alguna con respecto a la Ley 30/1992, de 26 de noviembre, de Régimen Jurídico de las Administraciones Públicas y del Procedimiento Administrativo Común, el artículo 128 , puntos $2 .^{\circ}$ y $3 .^{\circ}$ LPACAP, establece como límites al ejercicio de la potestad reglamentaria, por un lado, la cláusula general de reserva de ley, por otro, la prohibición específicade tipificar determinadas materias, sin perjuicio de la función de desarrollo o colaboración con la ley, y por último, el sometimiento al principio de jerarquía normativa ${ }^{12}$. Dispone el precepto citado:

«2. Los reglamentos y disposiciones administrativas no podrán vulnerar la Constitución o las leyes, ni regular aquellas materias que la Constitución o los Estatutos de Autonomía reconocen a la competencia de las Cortes Generales o de las Asambleas Legislativas de las Comunidades Autónomas. Sin perjuicio de su función de desarrollo o colaboración con respecto a la ley, no podrán tipificar delitos, faltas o infracciones administrativas (...).

3. Las disposiciones administrativas se ajustarán al orden de jerarquía que establezcan las leyes. Ninguna disposición administrativa podrá vulnerar los preceptos de otra de rango superior».

En el ámbito local no existe un orden de jerarquía de las disposiciones administrativas entre sí, de tal forma que más allá de la terminología de Ordenanzas y Reglamentos, ambos poseen rango reglamentario, y quizás la distinción comúnmente aceptada sea que las primeras regulan cuestiones ad extra, mientras que los segundos se reservan para la ordenación de las materias ad intra, y con la única salvedad (ésta sí que regulada expresamente por la ley, en lo que a su terminología se refiere) del Reglamento Orgánico Munici-

7 De acuerdo con el artículo 121 LRBRL:

a) los municipios cuya población supere los 250.000 habitantes.

b) los municipios capitales de provincia cuya población sea superior a los 175.000 habitantes.

c) los municipios que sean capitales de provincia, capitales autonómicas o sedes de las instituciones autonómicas

d) los municipios cuya población supere los 75.000 habitantes, que presenten circunstancias económicas, sociales, históricas o culturales especiales.

En los supuestos previstos en los párrafos c) y d), se exigirá que así lo decidan las Asambleas Legislativas correspondientes a iniciativa de los respectivos Ayuntamientos.

8 Las normas contenidas en los capítulos II y III del Título X de esta Ley, salvo los artículos 128, 132 y 137, serán de aplicación:

a) a los Cabildos Insulares Canarios de islas cuya población sea superior a 175.000 habitantes.

b) a los restantes Cabildos Insulares de islas cuya población sea superior a 75.000 habitantes, siempre que así lo decida mediante ley el Parlamento Canario a iniciativa de los Plenos de los respectivos Cabildos.

SÁNCHEZ GOYANES (2000): 105.

10 Vid. artículo 22 LRBRL y concordantes.

11 Muestra de ello en la Comunidad Autónoma de Galicia son v.gr. el «Consorcio das Mariñas»,y la «Mancomunidad de municipios de la comarca de Ferrol», que atribuyen en sus respectivos Estatutos la competencia normativa al Pleno.

12 MORA RUIZ (2016): 551-552. 
REALA. Nueva Época - N. ${ }^{\circ}$ 6, noviembre 2016 - ISSN: 1989-8975 - DOI: 10.24965/reala.v0i6.10391 - [Págs. 105-121]

Elaboración de disposiciones de carácter general en la Administración Local, tras la entrada en vigor de la Ley 39/2015

Alejandro Ramón Antelo Martínez

pal, que exige para su aprobación mayoría absoluta, sin que por ello su rango normativo sea superior al del resto de ordenanzas y reglamentos.

Sí que en cambio, los límites del ejercicio de esta potestad reglamentaria local, sin perjuicio de la reserva de ley, y de la lógica invulnerabilidad de la Constitución y de las leyes, exige, siguiendo a la doctrina más autorizada, unas importantes matizaciones.

En tal sentido, y en íntima conexión con la autonomía local consagrada por la Constitución, Parejo Alfonso defiende que:

«el poder normativo es pieza esencial 'de dicha autonomía', y que su integridad requiere la superación del concepto tradicional y firmemente establecido de la reserva de ley; en tal sentido, considera la pertinencia de su actualización por la vía de su entendimiento como técnica, en un Estado complejo, de asignación-reserva de las decisiones sobre los asuntos más relevantes o esenciales a los órganos más adecuados para su adopción: los colegiados directamente representativos» ${ }^{13}$.

Por lo que respecta al principio de jerarquía normativa, y concretamente a la subordinación de los reglamentos locales a las leyes (estatales o autonómicas, en los correspondientes ámbitos competenciales), Embid Irujo sostiene su necesaria modulación en función de la posición constitucional de las entidades locales, con apoyo en la legitimación democrática de la Administración Local, de modo que el principio de vinculación negativa de la potestad normativa local a la ley sería el cauce adecuado para ello, pudiendo reglamentarse todo aquello que la ley no le prohíba o excluya, y no solamente aquello que suponga un desarrollo de aquellas leyes del Estado o de las Comunidades Autónomas ${ }^{14}$.

Y en la misma línea, Velasco Caballero defiende la vinculación negativa de la ordenanza municipal a la ley, desde una

«comprensión negativa del principio de legalidad: la ley como límite y no como fundamento del poder normativo local. La relación entre la ley y las normas locales se define por el juego combinado de: el sometimiento general de las normas locales a la ley, cuando ésta existe (supremacía de la ley), y la exclusión de toda regulación local directa en ciertas materias (las reservadas por la Constitución a la ley)». De tal forma que en nuestro Derecho Local actual «se puede afirmar ya la licita existencia de normas locales independientes» ${ }^{15}$.

La jurisprudencia, por su parte, y como señalan los citados autores, también ha realizado avances en la configuración de la tesis de la vinculación negativa de la normativa local a la ley, y así, sin perjuicio de que venga reiterando que los reglamentos municipales están sometidos jerárquicamente a las leyes, $v$. gr. en sentencia del Tribunal Supremo de 20 de mayo de 1992:

«(...) entiende la Sala que la cuestión de jerarquía normativa (...) no se plantea en el caso de autos, pues nadie discute la sumisión de los reglamentos y ordenanzas locales a las leyes, estatales o de la Comunidad Autónoma según las respectivas competencias. Por tanto, el problema planteado no es en realidad el de la jerarquía normativa sino el de la ordinamentalidad del reglamento, es decir, si un reglamento de desarrollo de la Ley, como lo es la ordenanza local, puede incorporar nuevas reglas de Derecho al ordenamiento. A este respecto debe entenderse que efectivamente puede añadir dichas reglas en el sentido de aclarar, desarrollar y concretar los preceptos legales, dictar normas de procedimiento, y regular la organización, cuestiones todas ellas que forman parte del contenido de los reglamentos e indirectamente inciden en los derechos y deberes de los ciudadanos lo que pueden hacer, incluso condicionándolos ${ }^{16}$ »;

O en sentencia de 18 de diciembre de 1997:

«La Ordenanza cuya legalidad ahora enjuiciamos entra a regular situaciones de supremacía o sujeción general, al contener el régimen de apertura de ciertos establecimientos destinados

\footnotetext{
13 PAREJO ALFONSO (1998): 66.

14 EMBID IRUJO (2010): 110-126.

15 VELASCO CABALLERO (2009): 241, 242 y 248; y para una mejor comprensión del tema, Capítulo VII (235-332) in totum.

16 Aranzadi RJ 1992/4462.
} 
REALA. Nueva Época - N. ${ }^{\circ}$ 6, noviembre 2016 - ISSN: 1989-8975 - DOI: 10.24965/reala.v0i6.10391 - [Págs. 105-121]

Elaboración de disposiciones de carácter general en la Administración Local, tras la entrada en vigor de la Ley 39/2015

a la actividad privada de alquiler de vehículos sin conductor. En ella se expresan una serie de limitaciones y condicionantes para su ejercicio, que inciden directamente en el derecho a la libertad de empresa que como derecho fundamental consagra el artículo 38 de la Constitución, y que además exceden de los que con carácter general establece el artículo 9 del Reglamento de Servicios de las Corporaciones Locales de 17 junio 1955. Si a ello añadimos que se establecen una serie de infracciones y sanciones por determinadas conductas, concluiremos que se está lesionando el principio de reserva de ley que proclama el artículo 25 de la Constitución» ${ }^{17}$.

No es menos cierto, como afirma Velasco Caballero, que «el alcance real prescriptivo de estas sentencias puede ser severamente relativizado por tres razones»: a) porque hay sentencias en las que la exigencia de previa ley parte de la premisa de que en dicha materia existe constitucionalmente una reserva de ley; b) porque en algunas sentencias aquella exigencia de ley previa se satisface con el simple precepto que anuncia competencias municipales en determinadas materias, como p. ej. seguridad pública ex art. 25.2 LRBRL; c) y porque en algún otro caso la exigencia jurisprudencial de ley previa se realiza sobre la consideración de la competencia exclusiva del Estado en la materia, criterio que no toma en consideración que la Constitución solamente distribuye competencias entre el Estado y las Comunidades Autónomas, sin abordar las competencias locales ${ }^{18}$.

Este papel transformador de la jurisprudencia en la configuración de la teoría de la vinculación negativa de la ordenanza municipal a la ley, encuentra su punto de inflexión, según Embid Irujo ${ }^{19}$, en las sentencias del Tribunal Supremo de 29 de septiembre de 2003:

«(...) no puede ocultársenos que ello significa que existe una tensión entre el principio de autonomía local interpretado a la luz de la Carta Europea de 15 de octubre de 1985 y la reserva de ley que establece el artículo 25.1 de la Constitución para la tipificación de infracciones y sanciones. Pero entiende esta Sala que, no habiéndose planteado el Tribunal Constitucional un supuesto como el presente de competencias nucleares de los entes locales que llevan implícitas potestades de ordenamiento del uso del dominio (o eventualmente de organización de un servicio si es exclusivamente local), con fundamento en los artículos 55 y 59 del texto refundido de régimen local debe culminarse o extenderse a tales supuestos la tendencia de la propia jurisprudencia constitucional a flexibilizar el principio de reserva de ley. Por tanto, la tensión antes indicada debe resolverse en virtud de una interpretación integradora de un modo favorable al principio de autonomía local, admitiendo la posibilidad de esa tipificación por Ordenanza (...)» ${ }^{20}$;

$\mathrm{Y}$ de 25 de mayo de 2004:

«(...) parece cuando menos deseable una integración de la normativa actual que dé lugar a una interpretación de la misma en virtud de la cual se dote de sustantividad a la potestad reglamentaria de los entes locales, potestad ésta que reconoce de forma inequívoca nuestro ordenamiento jurídico. Pero es más. Este planteamiento debe hacerse teniendo en cuenta el principio de autonomía local que se reconoce en la Constitución española vigente, y que de algún modo podría entenderse contravenido o contradicho si uno de los elementos del contenido de esa autonomía, la potestad reglamentaria de los entes locales, se encuentra mermado y disminuido hasta el punto de que el Reglamento resulte infundamentado y en definitiva en ocasiones inaplicable. No se carece por completo de base normativa para llevar a cabo un nuevo enfoque interpretativo de la autonomía local $(\ldots) »^{21}$.

Posteriormente extendida, aunque con ciertos titubeos, a otros ámbitos sectoriales ajenos al ejercicio de la potestad sancionadora local, como el medio ambiente ${ }^{22}$, o la protección de la salud en la instalación de antenas de telefonía móvil ${ }^{23}$, en los cuales se ha ido abriendo paso y consolidándose la teoría de la vincula-

\footnotetext{
17 Aranzadi RJ 1997/9368.

18 VELASCO CABALLERO (2009): 249-250.

19 EMBID IRUJO (2010): 126-133.

20 Aranzadi RJ 2003/6487.

21 Aranzadi RJ 2004\4036.

22 Sentencia del Tribunal Supremo de 9 de diciembre de 2009; Aranzadi RJ 2010/2069.

23 Sentencia del Tribunal Supremo de 4 de mayo de 2010; Aranzadi RJ 2010/3577.
} 
REALA. Nueva Época - N. ${ }^{\circ}$ 6, noviembre 2016 - ISSN: 1989-8975 - DOI: 10.24965/reala.v0i6.10391 - [Págs. 105-121]

Elaboración de disposiciones de carácter general en la Administración Local, tras la entrada en vigor de la Ley 39/2015

Alejandro Ramón Antelo Martínez

ción negativa de la ordenanza municipal a la ley, sin menoscabo, obviamente, de las competencias estatales y autonómicas en los diferentes sectores.

\subsection{Planificación normativa ex ante}

Al igual que ocurre con el resto de las previsiones relativas al ejercicio de la potestad reglamentaria y de la iniciativa legislativa, la LPACAP contiene en su artículo 132 unas prescripciones de planificación normativa, sin distinción entre las diferentes Administraciones Públicas, y lo hace en los siguientes términos:

«1. Anualmente, las Administraciones Públicas harán público un Plan Normativo que contendrá las iniciativas legales o reglamentarias que vayan a ser elevadas para su aprobación en el año siguiente. 2. Una vez aprobado, el Plan Anual Normativo se publicará en el Portal de la Transparencia de la Administración Pública correspondiente».

Con carácter general, esta regulación no solamente está al servicio de la transparencia como explícitamente indica el punto segundo del precepto, sino también y muy significativamente, es una manifestación implícita del principio de seguridad jurídica al objeto de generar un marco jurídico predecible y de certidumbre.

Sin embargo, su implementación en el ámbito de la Administración Local, plantea dificultades e interrogantes en tres planos:

a) En primer lugar, los Entes Locales pueden establecer de manera autónoma un Plan Normativo con las iniciativas reglamentarias que prevean aprobar en el año siguiente, cuando se trate de elaborar y aprobar reglamentos independientes, dentro de los límites estudiados en el apartado anterior de este trabajo, o cuando aborden reglamentos ejecutivos (o de desarrollo, o complementarios de la ley) siempre que lo hagan con respecto a leyes estatales o autonómicas previamente aprobadas y no susceptibles de modificación en el ejercicio siguiente. En cambio, para el dictado del resto de estos reglamentos ejecutivos deberán estar a los planes normativos que apruebe el Estado y la Comunidad Autónoma respectiva en sus ámbitos competenciales, so pena de incurrir en una reglamentación contra legem.

b) En segundo lugar, y en íntima conexión con lo anterior, resultará preciso establecer (en vía reglamentaria) los plazos para la aprobación de estos planes normativos, y quizás, con el horizonte puesto en el cumplimiento del principio de seguridad jurídica, deberá preverse secuencialmente, de tal forma que los Entes Locales deban cumplir con esta obligación con posterioridad al Estado y a las Comunidades Autónomas, para una verdadera efectividad del mismo.

c) En tercer y último lugar, no prevé la Ley las consecuencias derivadas del incumplimiento o defectuoso cumplimiento de la obligación de aprobar este Plan normativo; concretamente cabe preguntarse si la falta de previsión de una iniciativa reglamentaria para el siguiente ejercicio en dicho Plan, determina la imposibilidad de abordarla ni tan siquiera por razones de urgencia debidamente motivadas.

En el ámbito de la Administración General del Estado, este Plan normativo está también previsto para el ejercicio de la iniciativa legislativa y reglamentaria del Gobierno en el artículo 25 de la Ley 50/1997, de 27 de noviembre, del Gobierno, de acuerdo con la nueva redacción que al mismo da la Ley 40/2015, de 1 de octubre, de Régimen Jurídico del Sector Público (LRJSP), y cuyo punto $3 .^{\circ}$ establece alguna solución al respecto, al disponer que, «cuando se eleve para su aprobación por el órgano competente una propuesta normativa que figurara en el Plan Anual Normativo al que se refiere el presente artículo, será necesario justificar este hecho en la correspondiente Memoria del Análisis de Impacto Normativo».

Fórmula en todo caso inaplicable, prima facie, a la Administración Local, pues en el procedimiento de elaboración de ordenanzas y reglamentos, no es preceptiva tal memoria de impacto normativo. 


\subsection{Principios de buena regulación}

Obedeciendo a better regulation y smart regulation, el artículo 129 consagra los principios de buena regulación a que debe sujetarse el ejercicio de la potestad reglamentaria, en nuestro caso local, y que se contraen a los siguientes: necesidad, eficacia, proporcionalidad, seguridad jurídica, transparencia y eficiencia, los cuales deberán quedar suficientemente justificados en el preámbulo de los proyectos de reglamentos u ordenanzas.

Santamaría Pastor ha dicho que el planteamiento de los mismos es «indiscutible», y que su enunciación:

«se asemeja a un retrato en negativo de lo que nuestro ordenamiento jurídico es y ha sido siempre: su lectura produce la impresión de que los redactores hubieran confeccionado un listado de todos los vicios y disfunciones posibles del ordenamiento español, plasmando sus directrices opuestas para corregirlos» ${ }^{24}$.

Estos principios no aparecen ex novo en nuestro ordenamiento jurídico por obra de la LPACAP, puesto que como afirma el Consejo de Estado en su Dictamen 275/2015:

«son los mismos que los que establece el artículo 4 de la Ley 2/2011, de 4 de marzo, de Economía Sostenible, bajo la rúbrica principios de buena regulación aplicables a las iniciativas normativas de las Administraciones Públicas, aún cuando la formulación concreta de unos y otros difiera en algunos puntos».

Ya el propio Consejo de Estado, en su Dictamen 215/2010, emitido en relación al anteproyecto de Ley de Economía Sostenible, afirmó que:

«los principios proclamados en ese artículo 4 están plenamente en línea con los criterios que este Consejo ha venido históricamente sentando en sus consultas sobre todo tipo de iniciativas normativas», si bien advirtió que los referidos principios "no se circunscriben a un determinado sector de la actividad administrativa de índole reguladora, puesto que, por su alcance general, tienen vigencia y pleno sentido en cualquier actuación de tal naturaleza, y por ello, deben positivizarse como exigencia general e indeclinable de toda iniciativa normativa que se propongan las Administraciones Públicas».

Además de las bendiciones del Consejo de Estado, la incorporación de estos principios del derogado artículo 4 de la Ley de Economía Sostenible a la LPACAP, implica, como afirma Mora Ruiz, que «el ejercicio de una potestad discrecional como la reglamentaria se somete ahora a un control adicional, (...) pues se impone la obligación de motivar en qué medida los principios 'de buena regulación' son observados» ${ }^{25}$.

a) Principios de necesidad y eficacia: en su virtud, «la iniciativa normativa debe estar justificada por una razón de interés general, basarse en una identificación clara de los fines perseguidos y ser el instrumento más adecuado para garantizar su consecución». Estos principios, entiende Mora Ruiz, operan a modo de tándem, aunque vinculados al principio de necesidad, ya definido en nuestro ordenamiento jurídico por la Ley 20/2013, de 9 de diciembre, de garantía de la unidad de mercado, de modo tal que la regulación no constituya un obstáculo para el ejercicio de la actividad económica ${ }^{26}$.

b) Principio de proporcionalidad: de acuerdo con el cual,

«la iniciativa que se proponga deberá contener la regulación imprescindible para atender la necesidad a cubrir con la norma, tras constatar que no existen otras medidas menos restrictivas de derechos, o que impongan menos obligaciones a los destinatarios».

Este principio, íntimamente vinculado al de necesidad, lleva implícito la obligación de valorar la opción cero en el ejercicio de la potestad reglamentaria local, si se constata que esa regulación imprescindible para conseguir los fines que se persiguen, se alcanza con otras normas ya existentes en el ordenamiento jurídico. Incluso se ha planteado la posibilidad de dar cumplimiento a estos principios a través de técnicas de soft law ${ }^{27}$.

\footnotetext{
24 SANTAMARÍA PASTOR (2016): 36.

25 MORA RUIZ (2016): 521-523.

26 MORA RUIZ (2016): 524.

27 BURGAR ARQUIMBAU (2016): 925.
} 
REALA. Nueva Época - N. ${ }^{\circ}$ 6, noviembre 2016 - ISSN: 1989-8975 - DOI: 10.24965/reala.v0i6.10391 - [Págs. 105-121]

Elaboración de disposiciones de carácter general en la Administración Local, tras la entrada en vigor de la Ley 39/2015

Alejandro Ramón Antelo Martínez

c) Principio de seguridad jurídica: con el fin de garantizar su observancia,

«la iniciativa normativa se ejercerá de manera coherente con el resto del ordenamiento jurídico, nacional y de la Unión Europea, para generar un marco normativo estable, predecible, integrado, claro y de certidumbre, que facilite su conocimiento y comprensión y, en consecuencia, la actuación y toma de decisiones de las personas y empresas».

La coherencia de los reglamentos locales con el ordenamiento nacional, estatal y autonómico, viene obligada por los principios de jerarquía normativa y reserva de ley, cuando de reglamentos ejecutivos o de desarrollo se trata, y en el caso de los reglamentos independientes, se asegura igualmente, de acuerdo con la jurisprudencia examinada, con la indemnidad de la legislación estatal y autonómica a través del principio de vinculación negativa a la ley. Pero además, con respecto al artículo 4 de la Ley de Economía Sostenible, este precepto recoge expresamente la obligación de coherencia con el «ordenamiento de la Unión Europea», lo cual implica una reflexión en el ámbito local, ya que efectivamente puede haber una colisión entre el derecho interno y el derecho comunitario en supuestos tales como el incumplimiento de plazos para la transposición de directivas comunitarias, o en casos de transposición defectuosa de las mismas, que pueden determinar la incidencia de los principios de primacía y efecto directo vertical ${ }^{28}$ en el ejercicio de la potestad reglamentaria local. El Tribunal Constitucional en su relevante sentencia 145/2012, de 2 de julio, estableció:

«Debemos recordar que el principio de primacía del Derecho de la Unión Europea forma parte del acervo comunitario incorporado a nuestro ordenamiento en virtud de la Ley Orgánica 10/1985, de 2 de agosto, de autorización para la adhesión de España a las Comunidades Europeas, y su efecto vinculante se remonta a la doctrina iniciada por el entonces Tribunal de Justicia de las Comunidades Europeas con la Sentencia de 15 de julio de 1964, asunto Costa contra Enel, habiéndose aceptado la primacía del Derecho de la Unión Europea, en el ámbito competencial que le es propio, por la propia Constitución Española en virtud de su art. 93, como hemos tenido ocasión de recordar en repetidas ocasiones. En concreto nos hemos referido expresamente a la primacía del Derecho comunitario como técnica o principio normativo destinado a asegurar su efectividad en nuestra sentencia 28/1991, de 14 de febrero, con reproducción parcial de la SentenciaSimmenthal del Tribunal de Justicia de las Comunidades Europeas de 9 de marzo de 1978, y en la sentencia 64/1991, de 22 de marzo. En nuestras posteriores sentencias 130/1995, de 11 de septiembre, 120/1998, de 15 de junio y 58/2004, de 19 de abril, reiteramos el reconocimiento de esa primacía de las normas del ordenamiento comunitario, originario y derivado, sobre el interno, y su efecto directo para los ciudadanos, asumiendo la caracterización que de tal primacía y eficacia había efectuado el Tribunal de Justicia, entre otras, en sus conocidas y ya antiguas Sentencias Vand Gend en Loos, de 5 de febrero de 1963, y Costa contra Enel, de 15 de julio de 1964, ya citada. Asimismo es pertinente traer a colación la doctrina fijada en la Declaración 1/2004, de 13 de diciembre, en la que precisamos que la primacía no se sustenta necesariamente en la jerarquía, "sino en la distinción entre ámbitos de aplicación de diferentes normas, en principio válidas, de las cuales, sin embargo, una o unas de ellas tienen capacidad de desplazar a otras en virtud de su aplicación preferente o prevalente debida a diferentes razones", lo que obliga al Juez nacional o a la Administración pública, en su caso, a aplicar la norma prevalente y a dejar sin efecto a la norma desplazada, aun cuando no haya sido expulsada del ordenamiento interno (algo propio de la Unión Europea como proceso de creación de una unidad política por agregación o unión de Estados)» ${ }^{29}$.

El Consejo Consultivo de Aragón, en su Dictamen 2/2012, de 6 de marzo se ha referido a la seguridad jurídica en estos términos:

«este principio que ha sido básico y determinante en nuestra historia jurídica y que obtiene hoy reconocimiento en el art. 9.3 nuestra Carta Magna (y que se traduce esencialmente en que pue-

28 Excede ampliamente el objeto de este trabajo el tratamiento exhaustivo de los principios de primacía y efecto directo del Derecho comunitario, en relación con el Derecho interno español. Para un análisis general y exhaustivo de los mismos, MANGAS MARTíN y LIÑÁN NOGUERAS (2006): 389-450; y GARCÍA URETA (2013): 141-183.

29 Aranzadi RTC 2012/145; la letra negrita es nuestra. 
da ser extraída certidumbre de los contenidos del ordenamiento, de manera que los sujetos que a él se someten sepan en todo momento a qué reglas han de atener sus comportamientos), no implica siempre y necesariamente estabilidad. Ésta es ciertamente deseable, si bien, debe ser obligadamente enmarcada en un ordenamiento en mejoramiento continuo e indefinidamente perfectible. Para lograr este mejoramiento continuo, pueden y han de ser utilizadas técnicas como son las que prevén la evaluación a posteriori de los contenidos normativos (...)1 ${ }^{30}$.

Por su parte, el Tribunal Supremo en sentencia de 21 de noviembre de 2012 ha señalado que:

«el valor de la seguridad jurídica no es oponible sin más a una modificación reglamentaria como argumento supuestamente invalidante de ésta, por más que desde otras perspectivas (también desde la muy frecuentemente invocada, del favorecimiento de las inversiones) sea deseable una cierta estabilidad de los marcos reguladores de las actividades económicas. La seguridad jurídica no resulta incompatible con los cambios normativos desde la perspectiva de la validez de estos últimos (...) sino que protege relaciones de este orden bajo el principio rebus sic stantibus pero, insistimos, no puede contraponerse como argumento invalidatorio frente a cambios relevantes en la base de las situaciones subyacentes» ${ }^{31}$.

En todo caso debe advertirse, como así hace Chinchilla Peinado, que:

«el legislador no incorpora a la LPACPA las observaciones realizadas por el Consejo de Estado respecto a la conveniencia de especificar la infracción del Derecho de la Unión Europea como causa de nulidad de los reglamentos, lo cual permitiría a la Administración acudir a la revisión de oficio como mecanismo destinado a la depuración del ordenamiento jurídico» ${ }^{32}$.

En este sentido, conviene recordar que el artículo 47.2 LPACAP determina que «serán nulas de pleno derecho las disposiciones administrativas que vulneren la Constitución, las leyes u otras disposiciones administrativas de rango superior (...)», pero nada dice respecto del Derecho Comunitario, de tal forma que en este caso no podría acudirse a la revisión de oficio del artículo 106.2, reservado exclusivamente para los supuestos de concurrencia de alguno de los supuestos del artículo 47.2.

d) Principio de transparencia: en aplicación de este principio,

«las Administraciones Públicas posibilitarán el acceso sencillo, universal y actualizado a la normativa en vigor y los documentos propios de su proceso de elaboración, en los términos establecidos en el artículo 7 de la Ley 19/2013, de 9 de diciembre, de transparencia, acceso a la información pública y buen gobierno; definirán claramente los objetivos de las iniciativas normativas y su justificación en el preámbulo o exposición de motivos; y posibilitarán que los potenciales destinatarios tengan una participación activa en la elaboración de las normas».

Planteado con anterioridad, en términos mucho menos ambiciosos, por la Ley de Economía Sostenible, para la materialización de este principio la LPACAP remite a la Ley de transparencia, cuyo artículo 7 exige, ciñéndonos al ámbito local, que se publiquen: a) los proyectos de Reglamentos; b) las memorias e informes que conformen los expedientes de elaboración de los textos normativos; c) los documentos que, conforme a la legislación sectorial vigente, deben ser sometidos a un período de informe publicación durante su tramitación.

Además de ello, y por otro lado, la participación activa de los destinatarios en el ejercicio de la iniciativa normativa, aparece ampliamente desarrollado en el artículo 133 de la propia Ley 39/2015, que seguidamente estudiaremos, como una manifestación esencial del principio de transparencia.

Por último, y toda vez que este artículo 129 exige para dar cumplimiento al principio de transparencia, que se definan con claridad en el preámbulo los objetivos que persigue la iniciativa reglamentaria, resulta oportuno traer a colación nuevamente el Dictamen 2/2012 del Consejo Consultivo de Aragón, en el cual expresa la conexión de este mandato con «la motivación de la norma», de tal forma que dichos objetivos «no solo han de ser procedentes, convenientes y oportunos, sino que además, han de ser definidos en términos de claridad».

30 Aranzadi JUR $2015 \backslash 255587$.

31 Aranzadi RJ 2013\320.

32 CHINCHILLA PEINADO (2016): 92-93. 
e) Principio de eficiencia: en aplicación del mismo, «la iniciativa normativa debe evitar cargas administrativas innecesarias o accesorias y racionalizar, en su aplicación, la gestión de los recursos públicos». Se trata de un principio novedoso respecto a la Ley de Economía Sostenible, cuyo artículo 4 no lo contemplaba, y además, de un marcado carácter economicista, directamente vinculado al principio de simplificación administrativa reconocido en la Ley 20/2013, de 9 de diciembre, de garantía para la unidad de mercado ${ }^{33}$.

Fuera de los principios de buena regulación enumerados, el artículo 129.7 LPACAP prevé una especie de cláusula de cierre con respecto a los mismos, al disponer que:

«cuando la iniciativa normativa afecte a los gastos o ingresos públicos presentes o futuros, se deberán cuantificar y valorar sus repercusiones y efectos, y supeditarse al cumplimiento de los principios de estabilidad presupuestaria y sostenibilidad financiera».

Parece, en definitiva, que el sistema de buena regulación se supedita al cumplimiento de los principios de estabilidad presupuestaria y sostenibilidad financiera, con la dificultad añadida de valorar los ingresos y gastos derivados del ejercicio de la potestad reglamentaria, y además, no solamente los presentes, sino también los futuros ${ }^{34}$. Y la pregunta inicial, al hilo de la entrada en vigor de la Ley 39/2015, resulta obligada: ¿el incumplimiento de estos principios «económicos», aún cuando se cumpla con los de buena regulación, determinará la imposibilidad de ejercer la potestad reglamentaria en ese ámbito concreto?

Si ya de por sí el precepto es poco claro, el artículo 130.2 LPACAP añade más confusión con respecto a la sistemática del artículo 129, al disponer:

«Las Administraciones Públicas promoverán la aplicación de los principios de buena regulación y cooperarán para promocionar el análisis económico en la elaboración de las normas y, en particular, para evitar la introducción de restricciones injustificadas o desproporcionadas a la actividad económica».

Es decir que tales «principios de buena regulación» son imperativos en el ejercicio de la potestad reglamentaria ex artículo 129, y además de cumplir con ellos, la iniciativa normativa habrá de ajustarse a los de estabilidad presupuestaria y sostenibilidad financiera, y sin embargo, tanto unos como otros se establecen en términos de «fomento» en este artículo 130.2, lo cual contribuye, no solo desde una perspectiva sistemática, sino también sustantiva, a generar serias dudas en la interpretación de la norma.

En todo caso, y si como decíamos al comienzo de este epígrafe, los principios de buena regulación acotan el ejercicio de una potestad discrecional como es la reglamentaria, y ello obliga a la Administración Local a justificar su observancia, asimismo, y de acuerdo con el artículo 106.1 de la Constitución Españo$\mathrm{la}^{35}$, no debe olvidarse que su cumplimiento es revisable por parte de los tribunales del orden jurisdiccional contencioso-administrativo. En este sentido, la reiterada jurisprudencia del Tribunal Supremo ha dicho, entre otras en sentencia de 1 de diciembre de 1986 que:

«El genio expansivo del Estado de Derecho ha determinado el alumbramiento de técnicas que permiten que el control jurisdiccional, tan ampliamente dibujado por el artículo 106.1 de la Constitución, se extienda incluso a los aspectos discrecionales de las potestades administrativas. Nuestra jurisprudencia ha acogido los logros doctrinales producidos al respecto, aplicándolos reiteradamente: a) en primer lugar, a través del control de los hechos determinantes, que en su existencia y características escapan a toda discrecionalidad: los hechos son tal como la realidad los exterioriza, no le es dado a la Administración inventarlos o desfigurarlos aunque tenga potestades discrecionales para su valoración; b) y, en segundo lugar, mediante la contemplación de la actividad discrecional a la luz de los principios generales del Derecho -artículo 1.4 del Código Civil-, que

${ }_{33}$ Cuyo artículo 7 establece: «La intervención de las distintas autoridades competentes garantizará que no genera un exceso de regulación o duplicidades y que la concurrencia de varias autoridades en un procedimiento no implica mayores cargas administrativas para el operador que las que se generaría con la intervención de una única autoridad»; MORA RUIZ (2016): 530-531.

34 Desde una perspectiva distinta, el Consejo de Estado ha dicho en su Dictamen 275/2015 que con esta previsión, junto con la relativa al principio de eficiencia, se lleva a cabo una suerte de desdoblamiento del contenido del artículo 7 de la Ley Orgánica 2/2012, de 27 de abril, de estabilidad presupuestaria y sostenibilidad financiera, dedicado al «principio de eficiencia en la asignación y utilización de los recursos públicos», estimando preferente que el Anteproyecto de Ley remitiera directamente a dicho precepto.

35 «Los Tribunales controlan la potestad reglamentaria y la legalidad de la actuación administrativa, así como el sometimiento de ésta a los fines que la justifican». 
REALA. Nueva Época - N. ${ }^{\circ}$ 6, noviembre 2016 - ISSN: 1989-8975 - DOI: 10.24965/reala.v0i6.10391 - [Págs. 105-121]

Elaboración de disposiciones de carácter general en la Administración Local, tras la entrada en vigor de la Ley 39/2015

Alejandro Ramón Antelo Martínez

al informar todo el ordenamiento jurídico son la atmósfera en la que respiramos jurídicamente, y por tanto también la norma habilitante que atribuye la potestad discrecional. La Administración no está sometida sólo a la Ley sino también al Derecho -artículo 103.1 Constitución Española-» ${ }^{36}$.

\subsection{Procedimiento de elaboración de normas reglamentarias}

El artículo 133 LPACAP articula ex novo un procedimiento de elaboración de ordenanzas y reglamentos, directamente vinculado al principio de transparencia, y a la participación activa de los ciudadanos en la iniciativa normativa, y que se estructura en dos fases diferenciadas:

Una primera, en la génesis del proyecto reglamentario (punto $1 .^{\circ}$, artículo 133 ):

«Con carácter previo a la elaboración de proyecto o anteproyecto de reglamento, se sustanciará una consulta pública, a través del portal web de la Administración competente, en la que se recabará la opinión de los sujetos y de las organizaciones más representativas potencialmente afectados por la futura norma, acerca de: a) los problemas que se pretenden solucionar (...), b) la necesidad y oportunidad (...), c) los objetivos (...), d) las posibles soluciones alternativas regulatorias y no regulatorias».

La segunda, una vez redactado el proyecto de reglamento u ordenanza (punto $2 .^{\circ}$, artículo 133):

«(...) cuando afecte a los derechos e intereses legítimos de las personas (...), se publicará el texto en el portal web correspondiente, con el objeto de dar audiencia a los ciudadanos afectados y recabar cuantas aportaciones adicionales puedan hacerse por otras personas o entidades (...)».

Secuencialmente se establecen, por tanto, un trámite de consulta y otro de audiencia e información pública, que suscitan dos dudas: en primer lugar, la referente a la identificación de las organizaciones más representativas potencialmente afectadas por la iniciativa reglamentaria, que puede dar lugar a ciertas distorsiones del principio de transparencia, mediante el riesgo de la captura de intereses ${ }^{37}$; y en segundo lugar, la vinculación del trámite de audiencia pública a la incidencia de la norma reglamentaria en los derechos e intereses legítimos de las personas, toda vez que resultará difícil identificar algún reglamento u ordenanza municipal que no vaya a dar lugar a esa afectación. Por eso, estas previsiones deben de complementarse con las del punto $4 .^{\circ}$, párrafo primero, del propio artículo 133, que permite «prescindir de los trámites de consulta, audiencia e información públicas en el caso de normas presupuestarias u organizativas, o cuando concurran razones graves de interés público que lo justifiquen»; de esta manera, se acota la discrecionalidad en la valoración de afectación de intereses particulares (que se excluyen ex lege, en el caso de normas organizativas o presupuestarias), y se plantea al mismo tiempo la necesidad de integración de un concepto jurídico indeterminado como es el de la concurrencia de razones graves de interés público.

Desde un punto de vista sustantivo, el punto $3 .^{\circ}$ de este artículo 133 exige que:

«la consulta, audiencia e información públicas reguladas en este artículo 'se realicen' de forma tal que los potenciales destinatarios de la norma y quienes realicen aportaciones sobre ella tengan la posibilidad de emitir su opinión, para lo cual deberán ponerse a su disposición los documentos necesarios, que serán claros, concisos y reunir toda la información precisa para poder pronunciarse sobre la materia».

Es decir, estos trámites no se articulan como meras formalidades, y para ello, resulta esencial que todos los documentos que han ido conformando acumulativamente el expediente administrativo, estén a disposición de los ciudadanos, para que se puedan realizar aportaciones con idéntico criterio que el órgano resolutorio, y precisamente encaminadas a ilustrar su decisión en el ejercicio de la potestad reglamentaria.

En último lugar, el precepto introduce una nueva indeterminación en su punto $4 .^{\circ}$, párrafo segundo, al disponer que:

36 Aranzadi RJ 1987/417.

37 MORA RUIZ (2016): 558. 
REALA. Nueva Época - N. ${ }^{\circ}$ 6, noviembre 2016 - ISSN: 1989-8975 - DOI: 10.24965/reala.v0i6.10391 - [Págs. 105-121]

Elaboración de disposiciones de carácter general en la Administración Local, tras la entrada en vigor de la Ley 39/2015

Alejandro Ramón Antelo Martínez

«cuando la propuesta normativa no tenga un impacto significativo en la actividad económica, no imponga obligaciones relevantes a los destinatarios o regule aspectos parciales de una materia, podrá omitirse la consulta pública regulada en el apartado primero».

Esto es, la consulta referente al trámite previo a la elaboración del anteproyecto o proyecto de reglamento u ordenanza. Nuevamente acude la Ley 39/2015 a una perspectiva economicista en su regulación (impacto económico), complementado con un nuevo concepto jurídico indeterminado (obligaciones relevantes), que en todo caso, solamente permitirán prescindir del trámite inicial de consulta, pero no del siguiente de información y audiencia públicas.

Se ha dicho que la LPACAP, en este precepto (al igual que en otros de este Título VI), realiza un función codificadora, y al respecto no puede obviarse que los trámites para el ejercicio de la potestad reglamentaria (y de la iniciativa legislativa) de las Administraciones Públicas ya aparecían previstos, de modo más diluido, en el derogado artículo 5 de la Ley 2/2011, de 4 de marzo, de Economía Sostenible:

«Para contribuir al objetivo de mejora de la calidad regulatoria y a la aplicación de los principios de sostenibilidad y buena regulación, las Administraciones Públicas:(...) 2. Prestarán la máxima atención al proceso de consulta pública en la elaboración de sus proyectos normativos, justificando entre otros los principios de buena regulación aplicables a las iniciativas normativas, fomentando la participación de los interesados en las iniciativas normativas, con el objetivo de mejorar la calidad de la norma. Para ello pondrán a disposición de los interesados todos los canales de comunicación necesarios, especialmente a través de medios telemáticos, y asimismo aportarán la información adecuada para la mejor comprensión y valoración de los efectos esperados de las iniciativas normativas».

Y que asimismo, las Comunidades Autónomas también habían regulado sobre esta materia, pudiendo servir de ejemplo al respecto la Ley 16/2010, de 17 de diciembre, de Administración General y Sector Público de Galicia ${ }^{38}$, pero lo cierto es que en el ámbito local, la nueva Ley de Procedimiento hace algo más que codificar, innova el ordenamiento jurídico ${ }^{39}$, equiparando el procedimiento de elaboración de reglamentos al establecido para el Estado y las Comunidades Autónomas, y ello lleva aparejadas relevantes consecuencias jurídicas.

En efecto, el procedimiento descrito se convierte en ius cogens, y su inobservancia puede invalidar la norma reglamentaria aprobada, como enseña el Tribunal Supremo en su sentencia de 11 de septiembre de 1998 , al declarar que,

«la finalidad del procedimiento de elaboración de las disposiciones generales, debe garantizar, ante todo, la legalidad, el acierto y la oportunidad de la misma y la interpretación de cualquier trámite del procedimiento de elaboración, debe hacerse conforme a la Constitución y conforme a todo el ordenamiento jurídico» ${ }^{40}$.

Y en la de 24 de febrero de 1999 al exponer taxativamente:

«La realidad es que la sentencia del Tribunal de Castilla-La Mancha declara la nulidad absoluta del acto impugnado 'acuerdo del Pleno por el que se deroga el Reglamento Orgánico', (...) obedeciendo su carácter antijurídico a la infracción de lo dispuesto en el artículo 49 de la Ley de Bases de Régimen Local; en consecuencia proclama su nulidad radical, no por defecto de las formalidades, convalidables o no, que la normativa vigente exige para la aprobación de un Reglamento (...) sino por la abierta y total contravención que este acuerdo concreto implica frente a los preceptos legales vigentes que regulan la materia, al pretender sustituir el procedimiento legalmente establecido por otro totalmente arbitrario y desprovisto de cobertura legal» ${ }^{41}$.

38 Vid. artículos 41 a 43.

39 Más allá de las previsiones esquemáticas del artículo 7 de la Ley 19/2013, de 9 de diciembre, de transparencia, acceso a la información pública y buen gobierno, de acuerdo con el cual, las Administraciones Públicas, incluidos los Entes que integran la Administración Local, publicarán «los proyectos de Reglamentos cuya iniciativa les corresponda».

40 Aranzadi RJ 1998/9942.

41 Aranzadi RJ 199911387. 
Ahora bien, si resulta posible la impugnación directa de una ordenanza o reglamento local ante la jurisdicción contencioso-administrativa, por omisión del procedimiento de elaboración descrito o de alguno de sus trámites esenciales, recurso que habrá de plantearse en el plazo de dos meses contados desde el día siguiente al de la publicación de la disposición, más dificultades planteará el recurso indirecto previsto en el artículo 26 de la Ley 29/1998, de 13 de julio, reguladora de la Jurisdicción Contencioso-Administrativa, una vez transcurrido aquel plazo preclusivo, y que como es sabido, es admisible con carácter general contra los actos que se produzcan en aplicación de las mismas, fundado en que tales disposiciones no son conformes a Derecho.

Afirman, en esta línea argumental, González Pérez y González Navarro, que:

«es dominante la doctrina 'legal' que establece que las infracciones procedimentales en que se hubiere podido incurrir en la elaboración de un reglamento, sólo podrán alegarse como fundamento de un recurso directo, pero no de un recurso indirecto» ${ }^{42}$.

En este sentido, y por todas las referidas por los citados autores, pueden señalarse las sentencias del Tribunal Supremo de 17 de noviembre 1993:

«(...) en la impugnación indirecta de disposiciones de carácter general con ocasión de combatir los actos de aplicación individual de las mismas no cabe aducir las supuestas irregularidades del procedimiento seguido al dictarlas, al no tratarse de vicios que produzcan la nulidad de pleno derecho conforme al art. 47 de la Ley de Procedimiento Administrativo 'de 1958' siendo tan sólo posible su anulación, con base en tales irregularidades a través del recurso de impugnación directa» ${ }^{43}$.

Y de 28 de septiembre de 1994:

«(...) basta recordar, sin necesidad de examinar la patente falta de consistencia de la alegación, que es constante la jurisprudencia de esta Sala [entre otras, Sentencias de 29 octubre 1987, 11 marzo y 27 noviembre 1989, y 17 noviembre 1993], que impide invocar como fundamento de un recurso indirecto contra reglamentos las irregularidades que se pretenden cometidas en su proceso de elaboración» ${ }^{44}$.

\subsection{Evaluación normativa ex post}

Los principios de better regulation y smart regulation configuran la actividad reglamentaria como un ciclo de mejora continua, para lo cual resulta necesario evaluar los resultados ${ }^{45}$, y su plasmación se encuentra en el artículo 130.1 LPACAP, cuyo párrafo primero establece:

«Las Administraciones Públicas revisarán periódicamente su normativa vigente para adaptarla a los principios de buena regulación y para comprobar la medida en que las normas en vigor han conseguido los objetivos previstos y si estaba justificado y correctamente cuantificado el coste y las cargas impuestas en ellas».

Evaluación ex post de los reglamentos y ordenanzas locales, que se plantea no solamente en términos de buena regulación, sino también nuevamente con parámetros economicistas, de modo que la iniciativa reglamentaria no solo ha de obedecer a la necesidad de legislar mejor, sino también a hacerlo de manera eficiente.

La puesta en marcha del control posterior de las normas locales exige un desarrollo reglamentario (local), por imperativo del párrafo segundo de este artículo 130.1:

«El resultado de la evaluación se plasmará en un informe que se hará público, con el detalle,

42 GONZÁLEZ PÉREZ y GONZÁLEZ NAVARRO (2007): 1513.

43 Aranzadi RJ 1993/8220.

44 Aranzadi RJ 1994/7117.

45 BURGAR ARQUIMBAU (2016): 929. 
REALA. Nueva Época - N. ${ }^{\circ}$ 6, noviembre 2016 - ISSN: 1989-8975 - DOI: 10.24965/reala.v0i6.10391 - [Págs. 105-121]

Elaboración de disposiciones de carácter general en la Administración Local, tras la entrada en vigor de la Ley 39/2015

Alejandro Ramón Antelo Martínez

periodicidad y por el órgano que determine la normativa reguladora de la Administración correspondiente».

Además, se suscita nuevamente el interrogante en torno a las consecuencias jurídicas de un informe de evaluación desfavorable, no solo en orden al cumplimiento de los principios de buena regulación, sino también desde aquella perspectiva economicista; ¿dará lugar a la obligación de derogar el reglamento u ordenanza municipal, o exigirá simplemente una adaptación a las exigencias legales, que eventualmente pueda no ser cumplida?

El Anteproyecto de LPACAP preveía que este informe de evaluación se elaborase e hiciese público con periodicidad anual, al objeto de acompasarlo a la planificación normativa, igualmente anual, a que están obligadas las Administraciones Públicas, sin embargo, el Consejo de Estado formuló observaciones a dicha anualidad en su Dictamen 275/2015, considerando lo que ya dijera en el Dictamen 215/2010 sobre el entonces anteproyecto de Ley de Economía Sostenible, esto es, «que la periodicidad anual con que se regulan los instrumentos de mejora de la regulación es poco realista, lo que entraña el riesgo de privar de auténtica utilidad a tales actuaciones».

\section{SUBSISTENCIA DEL PROCEDIMIENTO DE APROBACIÓN DE REGLAMENTOS LOCALES}

El «procedimiento de elaboración» de ordenanzas y reglamentos locales diseñado por la LPACAP, no afecta al «procedimiento de aprobación» de los mismos establecido en el artículo 49 LRBRL, el cual permanece vigente. De tal forma que concluido el detallado proceso de elaboración, se procederá a la aprobación inicial por el Pleno de la Corporación (u órgano competente de las entidades públicas no territoriales o asociativas), y a un nuevo trámite de información pública y audiencia a los interesados por el plazo mínimo de treinta días para la presentación de reclamaciones y sugerencias, con la posterior resolución de las mismas y aprobación definitiva, o bien con esta aprobación definitiva de manera automática en caso de ausencia de observaciones en el trámite de información pública.

A diferencia de los trámites de consulta e información pública del procedimiento de elaboración reglamentaria, prescindibles en los supuestos detallados en el artículo 133 LPACAP, este de información pública del procedimiento de aprobación no es sustituible en ningún caso, bajo pena de nulidad absoluta de la ordenanza o reglamento en cuestión, de forma tal que se puede afirmar que el ejercicio de la iniciativa normativa en el ámbito local se ha adelantado ampliamente en el tiempo a las previsiones de la Ley de transparencia, de la Ley del gobierno y de las leyes autonómicas reguladoras de esta materia, dando entrada a la participación ciudadana en consonancia con la «Administración cercana al ciudadano» que es, y que siempre la ha caracterizado.

Resulta necesario recordar que nuestra Carta Magna consagró el trámite de audiencia en su artículo 105 a), al disponer que «la ley regulará la audiencia de los ciudadanos, directamente o a través de las organizaciones y asociaciones reconocidas por la ley, en el procedimiento de elaboración de las disposiciones administrativas que les afecten».Y que con anterioridad al texto constitucional, solo de manera muy tímida la Ley de Procedimiento Administrativo de 1958, establecía para la Administración del Estado, en su artículo 130.4, alguna previsión al respecto, en los siguientes términos:

«Siempre que sea posible y la índole de la disposición lo aconseje, se concederá a la organización sindical y demás entidades que por ley ostenten la representación o defensa de intereses de carácter general o corporativo afectados por dicha disposición, la oportunidad de exponer su parecer en razonado informe, en el término de diez días a contar desde la remisión del proyecto, salvo cuando se opongan a ello razones de interés público debidamente consignadas en el anteproyecto».

Con respecto a la posible omisión de este trámite, ya el Tribunal Supremo en sentencia de 10 de marzo de $1992^{46}$ estableció su carácter esencial para que los interesados en particular y los administrados en general puedan invocar lo que en defensa de sus intereses estimen pertinente, garantizando la participación ciudadana en la elaboración de una disposición general, y determinando que la infracción del trámite lleve aparejada la nulidad de pleno derecho de la disposición impugnada.

46 Aranzadi RJ 1992/2140. 


\section{EFICACIA DE LAS DISPOSICIONES REGLAMENTARIAS LOCALES}

Como condición de eficacia, el artículo 131 LPACAP exige que los reglamentos se publiquen en el diario oficial correspondiente para que entren en vigor y produzcan efectos jurídicos, sin perjuicio de que las respectivas Administraciones Públicas establezcan facultativamente otros medios de publicidad complementarios.

El diario oficial de las entidades que integran la Administración Local es el Boletín Oficial de la Provincia respectivo, por imperativo del artículo $70.2 \mathrm{LRBRL}$, precepto que además establece un requisito adicional para la entrada en vigor de las ordenanzas y reglamentos locales, cual es el transcurso del plazo previsto en el artículo 65.2 de la propia LRBRL. Con carácter general, las normas (leyes y reglamentos) entran en vigor, de acuerdo con el artículo 2.1 del Código Civil a los veinte días de su completa publicación (...) si en ellas no se dispusiera otra cosa. Pues bien, en el ámbito local, además de esta completa publicación, es necesario que transcurra el plazo de quince días hábiles desde la recepción del acuerdo de aprobación por parte de la Administración General del Estado y de la Comunidad Autónoma respectiva ${ }^{47}$, y solamente con el cumplimiento acumulativo de estos dos requisitos, se producirá la eficacia y entrada en vigor de la norma reglamentaria.

Al respecto, el Tribunal Supremo puntualizó en su sentencia de 8 de marzo de 2000 que:

«la obligación contenida en el artículo 56.1 no impone la de remitir las actas de las sesiones, ni tampoco copia literal de las mismas, por los motivos ya recogidos en la anterior Sentencia de 15 de abril de 1988, alcanzando únicamente a la remisión de las copias o extractos suficientes de su contenido; obligación esta última que es, efectivamente, ineludible y que, ha de quedar bien claramente establecido, que ninguna Corporación Local se encuentra excusada de cumplir» ${ }^{48}$.

Por lo demás, este artículo 131 consagra en sus párrafos segundo y tercero, que la publicación electrónica de los diarios y boletines oficiales produzca la misma eficacia jurídica que venía generando la edición impresa de los mismos ${ }^{49}$, lo cual, por otra parte, ya había dispuesto con mucha antelación respecto al Boletín Oficial del Estado, el Real Decreto 181/2008, al preceptuar en su artículo 2 que:

«el Boletín Oficial del Estado se publica en edición electrónica con arreglo a las condiciones que se establecen en este Real Decreto, así como en la Ley 11/2007, de 22 de junio, de acceso electrónico de los ciudadanos a los servicios públicos, y en su normativa de desarrollo».

Resta exponer que las previsiones del artículo 23 de la Ley del Gobierno, según nueva redacción dada por la LRJSP, en orden al comienzo de vigencia el 2 de enero o el 1 de julio siguientes a su aprobación, de «las leyes o reglamentos que impongan nuevas obligaciones a las personas física o jurídicas que desempeñen una actividad económica o profesional como consecuencia del ejercicio de ésta», limita su aplicación a la Administración General del Estado, sin que resulte por tanto extensible a la Administración Local.

\section{BIBLIOGRAFÍA}

BURGAR ARQUIMBAU, Joaquín Miguel (2016): "Adaptación de la normativa municipal al nuevo procedimiento administrativo: modificación de ordenanzas y reglamentos locales”, El Consultor de los Ayuntamientos, núm. 8, 30 de abril.

CANO MONTEJANO, José Carlos (2013): Informe Hiperregulación en la Unión Europea, Foro Europa Ciudadana, http://www.europaciudadana.org/, (consultado27/09/2016).

CHAVES GARCÍA, José Ramón (2016): «Percepción y sensaciones locales ante las Leyes 39 y 40/2015», El Consultor de los Ayuntamientos, núm. 8, 30 de abril.

47 El artículo 56.1 LRBRL establece que «las entidades locales tienen el deber de remitir a las Administraciones del Estado y de las Comunidades Autónomas, en los plazos y forma que reglamentariamente se determinen, copia o, en su caso, extracto comprensivo de los actos y acuerdos de las mismas; los Presidentes y de forma inmediata los Secretarios de las Corporaciones serán responsables del cumplimiento de este deber»; plazo que el Real Decreto 2568/1986, de 28 de noviembre, por el que se aprueba el Reglamento de Organización, funcionamiento y régimen jurídico de las Entidades Locales cifra en seis días posteriores a la adopción del acuerdo (artículo 196.3).

48 Aranzadi RJ 200012170.

49 SANTAMARÍA PASTOR (2016): 51. 
REALA. Nueva Época - N. ${ }^{\circ}$ 6, noviembre 2016 - ISSN: 1989-8975 - DOI: 10.24965/reala.v0i6.10391 - [Págs. 105-121]

Elaboración de disposiciones de carácter general en la Administración Local, tras la entrada en vigor de la Ley 39/2015

Alejandro Ramón Antelo Martínez

CHINCHILLA PEINADO, Juan Antonio (2016): «Validez y eficacia. Avances y retrocesos en la Ley 39/2015, del Procedimiento Administrativo Común de las Administraciones Públicas. Su incidencia en la Administración Local», Cuadernos de Derecho Local, número 41, Fundación Democracia y Gobierno Local.

EMBID IRUJO, Antonio (2010): La potestad reglamentaria de las Entidades Locales, 1. ${ }^{a}$ edición, lustel, Madrid.

GARCÍA URETA, Agustín (2013): Derecho de la Unión Europea, Parte General, Marcial Pons, Madrid.

GONZÁLEZ PÉREZ, Jesús y GONZÁLEZ NAVARRO, Francisco (2007): Comentarios a la Ley de Régimen Jurídico de las Administraciones Públicas y Procedimiento Administrativo Común (Ley 30/1992, de 26 de noviembre), Tomo I, Cuarta edición, Thomson Civitas, Cizur Menor (Navarra).

LLISET BORREL, Francisco (2001): Manual de Derecho Local, 3. a edición, El Consultor de los Ayuntamientos y de los Juzgados, Madrid.

MANGAS MARTÍN, Araceli y LIÑÁN NOGUERAS, Diego J. (2006): Instituciones y Derecho de la Unión Europea, Quinta edición, Tecnos, Madrid.

MORA RUIZ, Manuela (2016): «Iniciativa legislativa y potestad reglamentaria. Disposición derogatoria», La nueva Ley del Procedimiento Administrativo Común, (Director, Humberto GOSÁLBEZ PEQUEÑO), Wolters Kluwer, Las Rozas (Madrid).

PAREJO ALFONSO, Luciano (1998): La potestad normativa local, Marcial Pons/Diputación de Barcelona, Madrid/ Barcelona.

RIVERO ORTEGA, Ricardo (2016): «La administración electrónica en las Leyes 39 y 40/2015», Cuadernos de Derecho Local, número 41, Fundación Democracia y Gobierno Local.

RIVERO YSERN, José Luis (2014): «La crisis económica y la reforma del régimen jurídico de la Administración Local», La Reforma del Régimen Jurídico de la Administración Local, (Coordinadores Juan Antonio CARRILLO DONAIRE y Pilar NAVARRO RODRÍGUEZ), La Ley-El Consultor de los Ayuntamientos, Las Rozas (Madrid), 1. a edición.

SÁNCHEZ GOYANES, Enrique (2000): La potestad normativa del municipio español, El Consultor de los Ayuntamientos y de los Juzgados, Madrid.

SANTAMARÍA PASTOR, Juan Alfonso (2016): «Un nuevo modelo de ejercicio de las potestades normativas», Revista Española de Derecho Administrativo número 175.

VELASCO CABALLERO, Francisco (2009): Derecho Local. Sistema de fuentes, Marcial Pons, Madrid. 